\title{
REFLECTIONS
}

\section{Neuroscience, Joy, and the Well-Infant Visit That Got Me Thinking}

\section{Tamas Ungar, MD}

St. Anthony's Hospital/Franciscan Health System, Gig Harbor, Washington
Conflicts of interest: author reports none.

\section{CORRESPONDING AUTHOR}

Tamas Ungar MD

St. Anthony's Hospital/Franciscan Health

System

11567 Canterwood Blvd, NW

Gig Harbor, WA, 98332

ts.ungar@gmail.com

11567 Canterwood Blvd, NW

\begin{abstract}
This essay is the narrative of a seemingly routine well-infant visit and the joyful bond that unites mother and infant and is at the forefront of early infant brain development. An incredible story unfolds. Through this short discourse, I hope to offer a glimmer of insight into the very meaning of being human while encouraging the family physician to foster the mother-infant bond. I explore emerging implications in child mental health, ADHD and ASD; how even during brief interactions of the well-infant and postpartum visits, family physicians can impact the mental development of their little patients in a meaningful way.
\end{abstract}

Ann Fam Med 2017;15:80-83. https://doi.org/10.1370/afm.2013.
A seemingly routine well-infant visit has started me thinking. A firsttime mother brought her 4-month old male into my office for a routine check-up. The infant was bottle-fed, born at 36 weeks, playful, with adequate growth; the physical exam was unremarkable. I was just about to wrap up the visit, however, when his mother, a little preoccupied, asked me to recheck his eyes. "It's not that the baby can't see," she explained, "but often it seems like he is staring into blank space." It was difficult for her to pinpoint her exact concern, but during her casual daily interactions with the infant he seemed to recognize her voice, but was unable to localize it.

A little perplexed myself, I examined the infant's eyes. Cataracts were absent and the light reflex was symmetric. His gaze fixed intently on objects and he demonstrated the expected "visual behavior." He looked at me with gaping wide eyes. I looked closer. Then I playfully raised my eyebrows, at which point the infant broke into a hearty giggle.

Just then, something very important happened. I reassured the mother that the infant's vision seemed fine, but through this seemingly "cute" moment, I was also able to gauge his finely tuned mechanism of mutual gaze. And to think, how much attention developmental neurologists have paid to this simple mode of communication! Mutual gaze has been called a "hidden regulator." Because the parent is closest to the infant, it is mainly her gaze interactions during brief joyful moments that serve to develop the infant's ability to self-regulate emotion.

And why is that important? My little patient's mother listened eagerly. According to the literature, ${ }^{1}$ mutual gaze seems to be at the core of personality traits important in social situations, moral decision making, behaviors based on reason and judgement, resiliency to stress in childhood, the development of secure attachments with others, and the ability to keep attention... In plain words, mutual gaze interactions serve to develop the infant's own sense of "self" — not a small feat!

It is understood that this process is reflected in the early physiology of vision. ${ }^{2}$ The way infants almost reflexively fix their gaze on the face of the caregiver has been likened to imprinting in ducklings. Unlike animals, however, infants focus particularly on the eyes of the caregiver ${ }_{i}$ a very keen facial recognition during infancy seems to be a uniquely human trait. 
Proximity also seems to be the key. Because their eyes are not yet able to accommodate very well and their visual acuity is poor, anything closer or farther than approximately 8 to 10 inches from their face is blurred In fact, it is no coincidence that when nurturing, breastfeeding, and cuddling, women usually hold their infants at approximately this same distance.

"By the way," I asked the mother, "from what distance do you feed and cuddle your baby?" I suspected that the reason for her vague concern is that she felt frustrated with this mutual gaze interaction with her baby. Perhaps during bottle feeding, the infant is scanning and staring into blank space because he cannot see his mother's face from a distance-does she hold her infant close enough to allow him that emotional proximity?

In this way, I prompted her to come just a little closer during everyday moments of mutual play, feeding, and cuddling. I encouraged more frequent encounters of closeness and warmth, of playful interactions, and to embrace those quiet moments of tenderness in addition to merely providing for the necessities for a healthy child during the course of a busy and stressful day. Having tried this simple intervention, she reported quick improvement in her interactions with her baby. She was amazed at his responsiveness. His blank stares and seemingly aimless scanning have disappeared and he showed a playful and interactive behavior. He met all developmental and language milestones during his follow-up visits, and scored "low risk" on the Modified Checklist for Autism in Toddlers (M-CHAT). ${ }^{3}$

I was left, however, with ruminating thoughts and unanswered questions. As I recalled those wide-open eyes of my patient, I had the sense that something intrinsically human was happening in this moment of bonding between mother and infant. What is being transmitted in the mother-infant dyad that is so fundamental for us humans to even have evolved a unique set of visual mechanisms to pass it down to the next generation? What is the meaning of neurobiologists' reference to a "hidden regulator?" And how does this relate to the development of those desired psychologic traits that I mentioned above? Surely, my well-infant visit has got me thinking.

I turned to the work of the respected developmental neuro-psychologist, Dr Allan Schore. According to Schore ${ }_{1}^{4}$ part of the answer surprisingly boils down to one of the most basic human experiences: joy. Joy was communicated to my 6-month-old patient, which in return triggered in him a spontaneous burst of laughter. It was transmitted and registered through the many facial cues that are exchanged in those brief moments of mutual gaze, during bonding moments shared with the immediate caregiver. Further, these experiences may be relayed by that familiar neurotransmitter of the catecholamine family, dopamine. Incredibly, what seems to happen under the effect of bursts of dopamine throughout the mother-infant bond is a literal "ignition" of important regions of the infant's cortex, even by the direct modulation of genetic expression.

To describe this process, Harvard researchers utilized the term "serve-and-return." It begins as the infant naturally vies for interaction through babbling, cooing, and simply gazing and scanning. The very recognition that the infants are "cute" merits a response from the caregiver to reinforce the attention-seeking behavior. This process may be repeated many times through the course of a day, and through a fine interplay of neurotransmitters, seems to play an invaluable role in the formation of the infant's brain circuitry. ${ }^{6}$

Thinking back to my initial well-infant exam, therefore, it seems that through the close observation of my little patient I have, in-fact, come to appreciate something extraordinarily human, and now it became clear why. The joy that is transmitted through serve-andreturn interactions, perhaps the first uniquely human experience, seems to be strongly tied to the early development of the infant's brain, specifically, those parts of the brain which tend to integrate our "self" as individuals. These are important regions of the prefrontal cortex. It is this area of the brain through which human beings integrate their experiences to form a sense of self, learn to regulate their emotions, and develop social

\section{Figure 1. Mother and Child.}

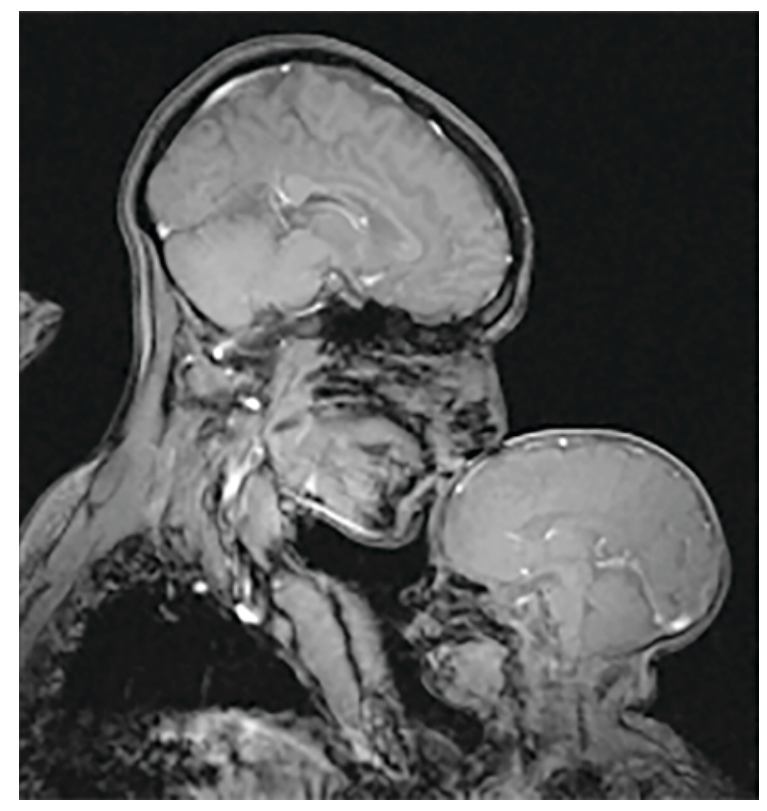

Reprinted courtesy of Rebecca Saxe and Atsushi Takahashi, Department of Brain and Cognitive Sciences, Massachusetts Institute of Technology, Cambridge, Massachusetts ( Athinoula A. Martinos Imaging Center at the McGovern Institute for Brain Research, MIT); Dec 2015 edition of the Smithsonian Magazine. 
interactions and healthy relationships. From a larger anthropological perspective, a robust prefrontal cortex is believed to represent a fundamental milestone in the evolution of the human brain $_{i}$ it is understood to be a requirement for the social creatures that we are. ${ }^{7}$ But the development of this structure seems to be a tedious undertaking, involving close dependence on the caregiver. We are not like the horses that are able to run as soon as they are born! Rather, through a fine interplay of nature and nurture, the infant's social brain needs time to grow and organize, which it does in close feedback from the parents.

We may be just beginning to understand the major role these brief, candid, even "hidden" moments between the infant and caregiver play in some of the important mental health issues of our time. Among other topics, there have been many recent implications of these concepts in Attention Deficit Hyperactivity Disorder (ADHD) and Autism Spectrum Disorders (ASD) research. It has been recently elucidated that infants who later develop ASD in their toddler years already seem to fail in key visual bonding mechanisms at approximately age 2 to 6 months. ${ }^{8}$ This failure may interfere with the serve-and-return process and set the course for an abnormal cascade of development, which may manifest in the later years. Recent research focused on premature neonates, a subset of patients traditionally known to be at higher risk for both ASD and ADHD, has confirmed decreased anatomical development of the prefrontal cortex. ${ }^{9}$ This, along with apparent underdevelopment of other regions of the brain that are postulated to be responsible for the "salient network" of abnormal visual and social connectivity, as well as altered ability to focus attention that characterize ASD and ADHD respectively.

Perhaps we are seeing a paradigm shift in focus in intervention in these illnesses to earlier age-groups. ${ }^{8}$ During later follow-up as infants-premature neonates who underwent structured bonding periods with their parents while they were still in the NICU-showed a "robust" increase in their resting EEG activity in the frontal cortical areas. ${ }^{10}$ During extensive psychological testing, these infants showed improvements in many areas relating to social development and attention skills compared to the control group, including significantly lower M-CHAT scores. The rigorous pilot study of Rogers et $\mathrm{al}^{11}$ introduced longitudinal programs based on mutual play and parent-infant bonding to infants diagnosed with early signs of ASD, resulting in reversal of these symptoms in some cases. Literature seems to be gaining momentum on interventions based on parent-infant mutual play, ${ }_{1}^{12}$ involving bonding interactions and mutual gaze, even in the earliest stages of development.
Our traditional concept of "early intervention" may simply not be early enough. Perhaps in the future, family doctors may be able to screen high-risk patients, and follow-through with referral to reimbursable programs based on parent-infant bonding at far earlier stages of life. Indeed, the research seems to be ample to start thinking of preventative care in infant mental health. For these concepts to take root, however, much work still needs to be done in education and advocacy. ${ }^{13}$ The goals of state-level associations of infant mental health, such as the highly successful pilot program of the Florida Association of Infant Mental Health (FAIMH), seem to aim towards just that. At the core of these programs lies a new approach of dealing with the parent-infant unit as a single patient, especially in high-risk cases such as child neglect. ${ }^{14}$ It certainly waits to see how these concepts will trickle into the consulting offices of clinicians working on the front lines of mother-infant care.

For now, however, my inspired musings as a family doctor have often given parents of postpartum and well-infant visits something to grasp at, something to appreciate and think about. As a start, I have counseled parents to have confidence in holding their infants close, to actively reinforce them in their efforts to babble and coo, to be mindful of opportunities for mutual play, and most of all, to encourage that basic natural joy in their interactions. Time permitting, I have discussed with parents the importance of mutual gaze, among other forms of bonding, as a deeply ingrained mechanism for the development of important parts of the brain, and to permit a healthy integration of the self through the transmission and regulation of emotion. I have often seen mothers' faces "light up" at our discussion, as I found the joy in their bond with their infants to be easily demonstrable.

Rebeca Saxe of the Brain and Cognitive Sciences department at MIT captured the scan of a woman with her baby through an MRI machine (Figure 1). ${ }^{15}$ The image depicts the mother-infant bond at the level of its most basic neuroanatomy. Through a grainy spectrum of black and grey, the infant brain-seemingly exposed and vulnerable-is held by a larger and more robust adult brain. The two are in close communication through a kiss to the infant's forehead, giving merit to the statement of Allan Schore, certainly to apply to our little patients in the office, that the developing brain forms in the setting of a relationship - a bonding relationship, with "another self-another brain."

To read or post commentaries in response to this article, see it online at http://www.annfammed.org/content/15/1/80.

Key words: child development; infant health; mother-child relations; autistic disorder; attention deficit disorder with hyperactivity; ADHD 
Submitted April 9, 2016; submitted, revised, August 17, 2016; accepted September 20, 2016.

\section{References}

1. Mantymaa M, et al. Shared pleasure in early mother-infant interaction: predicting lower levels of emotional and behavioral problems in the child and protecting against the influence of parental psychopathology. Infant Ment Health J. 2015;36(2):223-237.

2. Johnson MH, Senju A, Tomalski P. The two-process theory of face processing: modifications based on two decades of data from infants and adults. Neurosci Biobehav Rev. 2015;50:169-179.

3. M-CHAT. The M-CHAT (Modified Checklist for Autism in Toddlers). https://www.m-chat.org/mchat.php.

4. Schore A. Affect Regulation and the Origin of the Self. New York, NY: Routledge; 2015.

5. Center on the Developing Child, Harvard University. Serve and return. http://developingchild.harvard.edu/science/key-concepts/ serve-and-return/.

6. Center on the Developing Child, Harvard Univesity. Serve and return interaction shapes brain circuity (Video). http://developingchild. harvard.edu/.../serve-return-interaction-shapes-brain-

7. Falk D. Interpreting sulci on hominin endocasts: old hypotheses and new findings. Front Hum Neurosci. 2014;8:134.

8. Klin A, Shultz $S$, Jones W. Social visual engagement in infants and toddlers with autism: early developmental transitions and a model of pathogenesis. Neurosci Biobehav Rev. 2015;50:189-203.
9. Sample I. Brain scans of premature babies reveal changes that may raise risk of autism. The Guardian. May 4.2015. https://www. theguardian.com/science/2015/may/04/premature-babies-more-atrisk-of-autism-and-behavioural-conditions-scans-show.

10. Welch MG, Firestein MR, Austin J, et al. Family Nurture Intervention in the Neonatal Intensive Care Unit improves social-relatedness, attention, and neurodevelopment of preterm infants at 18 months in a randomized controlled trial. J Child Psychol Psychiatry. 2015; 56(11):1202-1211.

11. Davlantis K, Rogers S. The Early Start Denver model: a play-based intervention for young children with autism spectrum disorders. In: Reddy L, Files-Hall T, Schaefer C, eds. Empirically Based Play Interventions for Children. 2nd ed. Washington, DC:American Psychological Association; 2016:205-222.

12. Reddy L, Files-Hall T, Schaefer C, eds. Empirically Based Play Interventions for Children. 2nd ed. Washington, DC:American Psychological Association; 2016.

13. Shulman C. Applications of infant and early childhood mental health research in policy and practice. In: Research and Practice in Infant and Early Childhood Mental Health. New York, NY: Springer: 2016:203-218.

14. Zero-to-Three. Nurturing change: state strategies for improving infant and early childhood mental health. https://www.zerotothree. org/resources/122-nurturing-change-state-strategies-for-improvinginfant-and-early-childhood-mental-health. Published 2013.

15. Saxe R. Why I captured this MRI of a mother and child. http:// www.smithsonianmag.com/science-nature/why--captured-MRImother-child-180957207/. Published Dec 2015.

\section{Get the Annals of Family Medicine by E-mail}

Make sure you see every new issue

while it's fresh; have the table of

contents sent to you by e-mail for

easy access to articles of interest.

Don't miss important research.

Request the e-mail table of contents at

http://www2.highroadsolution.com/

aafp_annals_preference_center/search.aspx

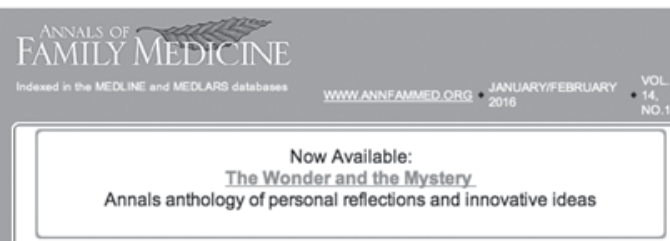

The full text of the journal is availabile online at hito aggregators, including PubMed Central, EBSCO, and MDConsult The A Anatsis is indexed in the
MEDLLINE and MEDLARS, Sclence Citation Index Expanded, Current Contents Clinical Medidine, MEDLINE and MEDLARS, Science Citation index
PSyclNFO, EMBASE, and CINHAL databases.

EDITORIALS

In This Issue: Size Maters

Achieving PCMH Staus May Not Be Meaningtul for Small Practices

Kelley K Glancer, James Q Kennedy

The Paradox of Size: How Small, independent Practices Can Thrive in Value-Based Carl

DRIGINAL RESEARCH

Solo and Small Practices: A Vital, Diverse Part of Primany Care

Winston R. Liew. Anum Family physicians in solo and small practices outnumber those in larger practices.

Large Indegendent Primary Caro Medical Groups

Lawrence P. Casalino; Melinda A. Chen; C. Todd Staub; Matthew J. Press; Jayme L Mendelsohn; John T. Lymch; Yesenia Mirara

arge physician-owned groups have the potential to make primary care attractive to physicians

Primary Care Physician Panel Size and Quality of Care: A Pooulation-Based Study in Ontario. Simada Dahrouge; WWwam Hogg; Jaime Younger, Elizaboeth Muggah; Grant Russell; Richard H. 